\title{
Nutritional implications for ultra-endurance walking and running events
}

\author{
Eric Williamson * (1)
}

\begin{abstract}
This paper examines the various nutritional challenges which athletes encounter in preparing for and participating in ultra-endurance walking and running events. Special attention is paid to energy level, performance, and recovery within the context of athletes' intake of carbohydrate, protein, fat, and various vitamins and minerals. It outlines, by way of a review of literature, those factors which promote optimal performance for the ultra-endurance athlete and provides recommendations from multiple researchers concerned with the nutrition and performance of ultra-endurance athletes. Despite the availability of some research about the subject, there is a paucity of longitudinal material which examines athletes by nature and type of ultra-endurance event, gender, age, race, and unique physiological characteristics. Optimal nutrition results in a decreased risk of energy depletion, better performance, and quicker full-recovery.
\end{abstract}

Keywords: Ultra-endurance, Energy, Nutrition, Performance, Training

\section{Background}

As a crucial aspect of the life of athletes, and a basic element of physical fitness, endurance is significantly impacted by not only physiological characteristics but very importantly, the body's capacity to effectively utilize nutrients to sustain performance, particularly during ultra-endurance events. Defined as events lasting at least $6 \mathrm{~h} \mathrm{[1]}$, ultra-endurance events place extreme and unique physiological demands on athletes. Some events span several days, including those that have no scheduled breaks [2]. The diversity in location in which these events are sometimes performed presents athletes with unique challenges including extreme temperatures, increase in altitudes, rapid energy depletion, and the need to consume nutrients during the event. Proper training is important to prepare for such extraordinary physical feats, but nutrition is paramount as these events would not be possible without adequate fuel availability. Nutrition, hydration, and recovery are among the most important considerations for athletes, which require advanced planning.

*Correspondence: eric.williamson@mail.utoronto.ca Department of Exercise Science, University of Toronto, 55 Harbord Street, Toronto, ON M5S 2W6, Canada
It has been identified that a comprehensive source providing succinct guidelines and recommendation to both protect the health of these athletes and promote performance is not available. Numerous case reports and field studies [3-24] show that few ultra-endurance runners and walkers meet recommendations that have been established throughout the literature. In an observational study of 42 amateur runners in a Swiss mountain marathon, researchers discovered that the intake of most participants were significantly below the requisite nutritional recommendations [7]. They further asserted that $90 \%$ of ultramarathon runners agreed that nutrition has an important influence on overall performance. This being said, adequate food and fluid intake is related to a successful finish of an ultra-endurance race $[7,24]$ and an important key to attaining this adequacy seems to be an appropriate nutrition strategy during the race [25]. These findings are possible indicators that the difficulty which athletes experience in meeting standard recommendations could be attributed to various factors. Among these are lack of or poor nutrition education, norms of ultraendurance sports, the development of physical symptoms including injury, gastrointestinal disturbances, suppression of appetite, logistic challenges with implications for both food preparation in terms of time and available 
resources/facilities to do so and, by extension, total food intake particularly in those periods of increased needs $[15,26,27]$. Additionally, dehydration and fluid overload $[14,26-29]$ appear to be areas with which have challenges. The myriad of stressors, such as extreme environmental conditions, intense physical exertion, limited sleep, and rationing of food, which ultra-endurance athletes encounter [14, 26-29], highlights the importance of prior planning where individualized nutrition strategy is concerned. It is clearly demonstrated throughout the literature that there is a need for appropriate education of ultra-endurance athletes, coaches, medical staff and race organizers, based on environmental conditions and course topography. Overarching goals should be aimed at minimizing the energy gap between intake and expenditure, attaining adequate dietary intakes of micronutrients and avoiding over or under hydration. This review will comprehensively discuss recommendations to address these issues.

\section{Review}

\section{Energy needs of the ultramarathon athlete}

As can be seen in Table 1, ultra-endurance events are highly diverse, but available literature suggest that they result in an energy deficit. Ultra-endurance athletes typically train for 1-6 h per day and many have multiple training sessions per day [30]. It is not uncommon to train for longer than $6 \mathrm{~h}$ at a time as some events require more than $24 \mathrm{~h}$ of continuous activity [30]. Therefore, as shown in Table 1, quantities of energy intake well above those of the average person are required to fuel the activity for both training sessions and events. With performance as a primary goal, athletes should strive to achieve an energy intake that matches the energy output of their activity, basal metabolic rate (BMR), thermic effect of food, and other activities of their daily life. It is important that ultra-endurance athletes consider these variables both during activity and outside the context of activity as failure to restore energy between training sessions can delay recovery and be detrimental to performance. Extreme energy deficits have been found to be a common feature among athletes who engage in continuous and multi-stage ultramarathon events. This is subsequently associated with poor recovery from exercise and sustained fatigue $[14,15]$. Both inadvertent symptoms such as gastrointestinal challenges and injury, including those that are dermatologically related, increase the risk of insufficient food and fluid intake with and without the addition of environmental challenges [31, 32]. In competition, field research suggests that ultra-endurance athletes finish their races with an energy intake between 36 and $54 \%$ of energy expenditure $[18,34]$. With this in consideration, Ramos-Campo et al. [33] have found that the magnitude of the energy deficit is correlated with performance, which suggests that reducing this energy deficit may be an advantage.

As in standard marathon runners, attaining an intake that is as close as possible to energy output should be a noteworthy ambition [35]. Both general and environment/activity-specific implications and strategies on how to do this will be discussed in the following sections. However, it should be recognized that other non-nutritional strategies to reduce the risk of inadequate energy intake, such as those to reduce gastrointestinal symptoms and injuries, play a role in achieving this. Common GI challenges that hinder intake include nausea, abdominal cramping, bloating, diarrhea, vomiting, flatulence, and belching $[26,36]$. These issues are more common as intensity and/or duration increase. Common injuries that hinder intake depend largely on the environment and climate and include blisters, subungual haematomas, chafings, abrasions, and plantar fasciitis [26, 37]. Climate and environmental-specific injuries include blisters and sunburns in hot temperatures, [26] and frostnip and frostbite in cold temperatures [37].

\section{Carbohydrate}

Given that the majority of an ultra-endurance athlete's training is spent engaged in lengthy durations of aerobic activity, many of these athletes are well adapted to utilizing lipids via oxidative phosphorylation [35]. However, the energy demands of their specific activity will vary, predominantly depending on the duration, intensity and type of exercise being engaged in [38]. Intensity, duration, and food intake will largely determine how much fuel is being sourced from carbohydrates $(\mathrm{CHO})$, protein, and fat. Although all three are being used as sources of energy at any given time, the intensity and duration are primary factors which determine the extent to which one is used over another. When the athlete is exercising at the standard marathon pace that requires $80-90 \%$ of maximal oxygen consumption $\left(\mathrm{VO}_{2} \max \right)$ or above, carbohydrate will be his or her primary fuel source and could provide up to $96 \%$ of the energy being expended [35]. However, at lower intensities in which sufficient oxygen can be achieved, such as walking, much more fuel could be provided from fat [39]. Therefore, the fraction of macronutrient utilization distribution is of considerable dependence on individual and exercise differences as well as carbohydrate availability, with lower availability forcing the body to depend more highly on fat and protein.

Based on the preceding discussion, as well as the observation that elite marathon running is nearly $100 \% \mathrm{CHO}$ dependent [40], awareness of $\mathrm{CHO}$ intake is important during training and events, especially those for which completion in minimal time is an objective. In fact, 


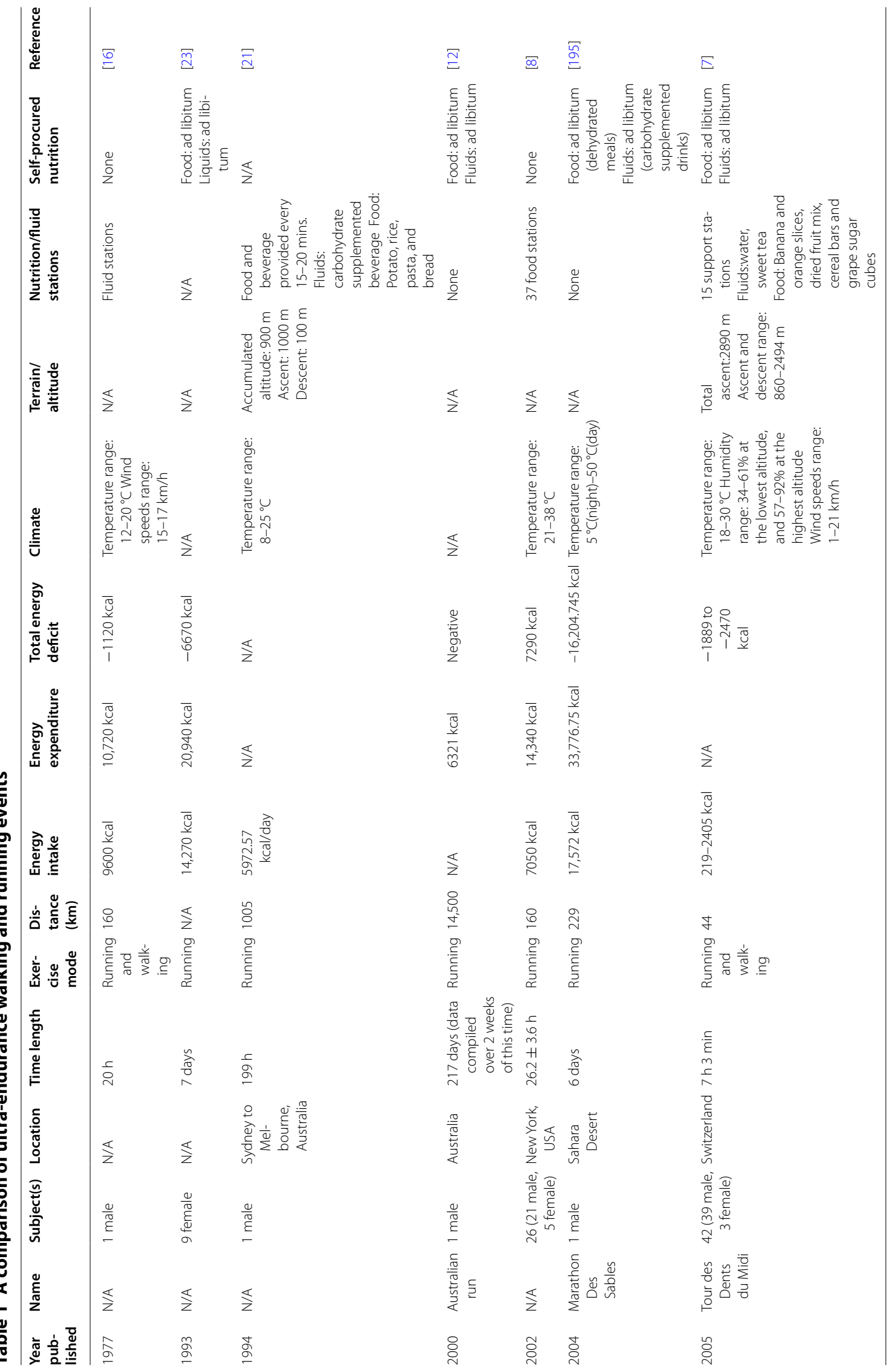




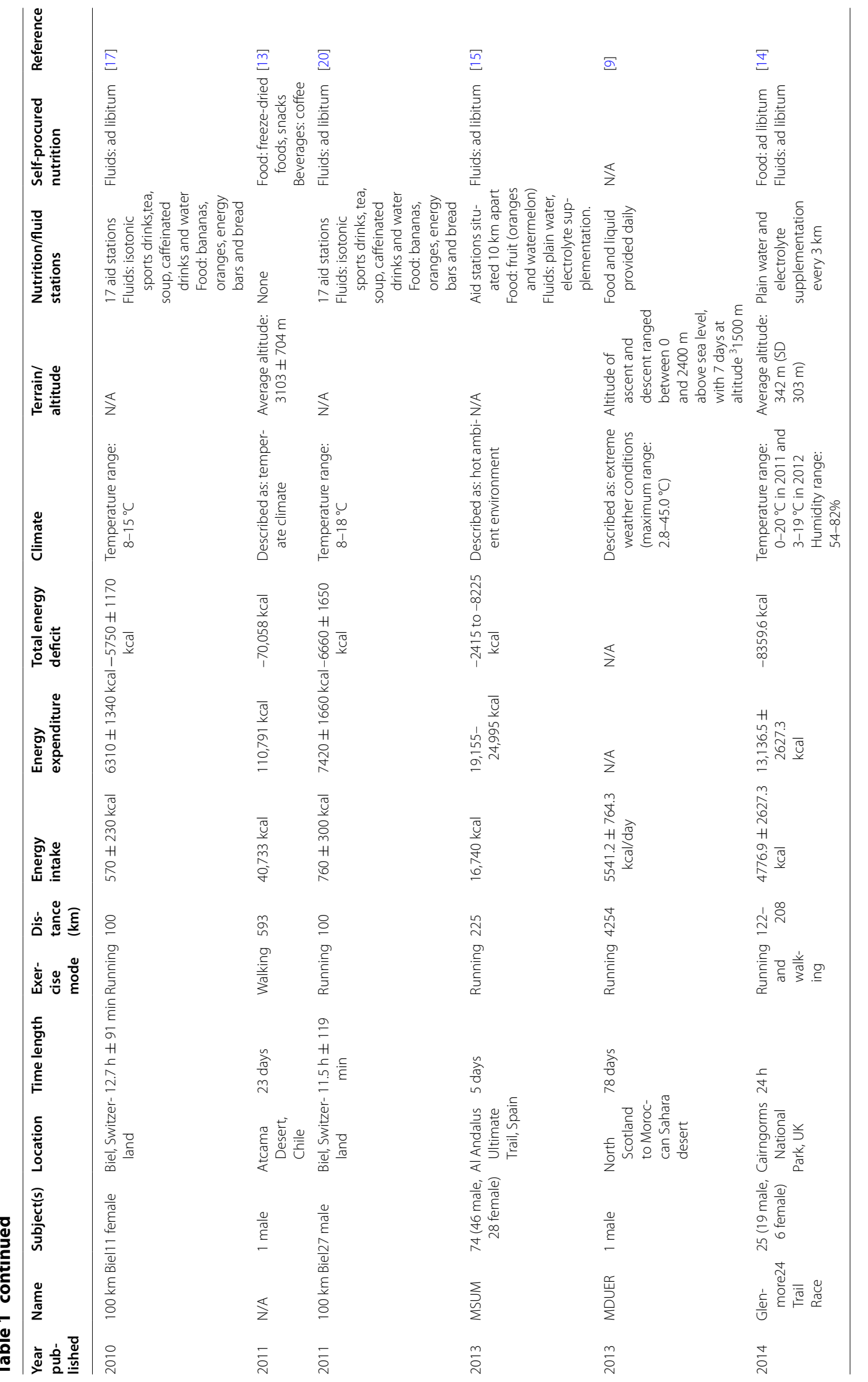




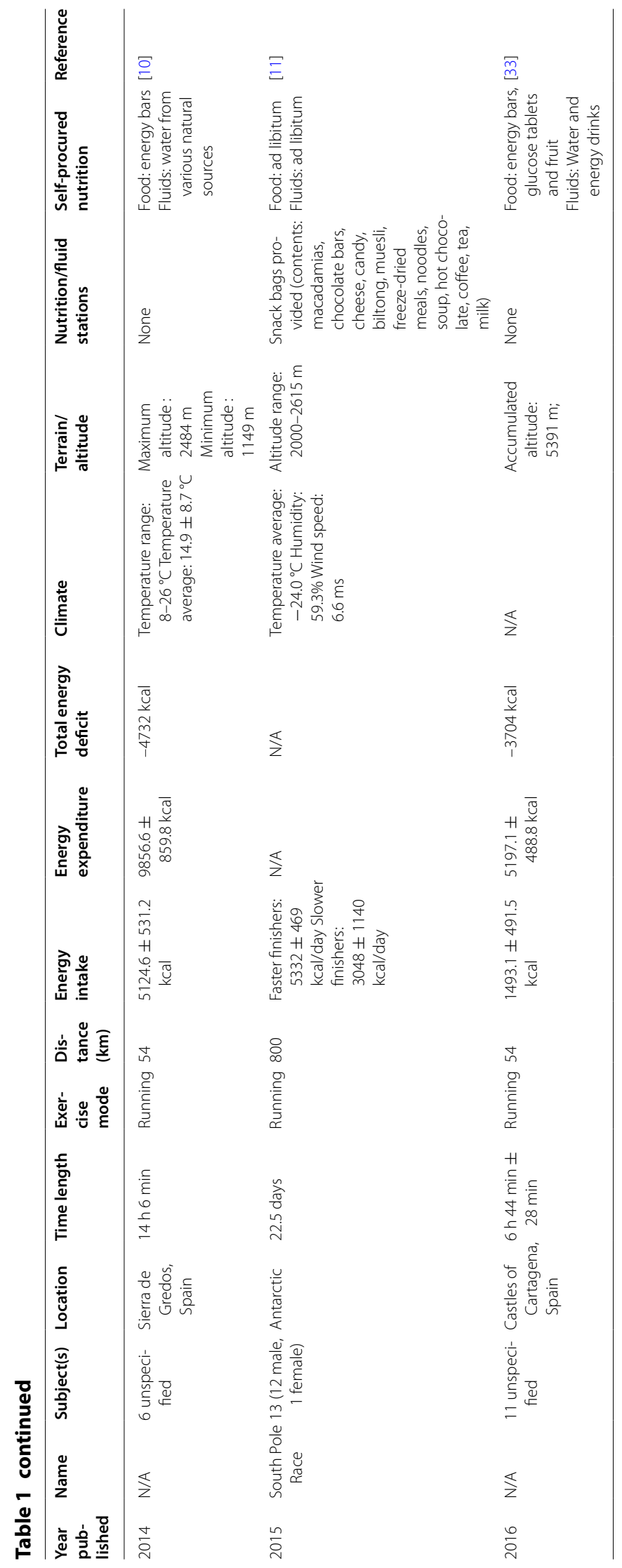


many studies have demonstrated that increases in the hourly rate of $\mathrm{CHO}$ and overall energy intake are correlated with faster race times in ultra-endurance events $[8,18,41]$. This suggests that athletes should strive to maximize availability of $\mathrm{CHO}$ for their working muscles and reinforce the need for adequate energy to maintain performance.

Glycogen provides a reserve of $\mathrm{CHO}$ for the body and low glycogen availability appears to be a stimulus for feelings of fatigue [42]. To maximize fuel storage as glycogen for events, a high carbohydrate diet is generally suggested between training sessions and events [43]. Current recommendations regarding specific recommendations for carbohydrate ingestion have recently been reviewed by Burke and Hawley [44]. Specifically, 8-12 g of $\mathrm{CHO} / \mathrm{kg}$ body weight/day is recommended, with a more precise amount dependent on the athlete's training intensity and duration [45]. This being said, the need for high carbohydrate intakes both before and during the event is dependent on whether carbohydrate fuel sources are depleted or limiting for the demands. Increases in intensity, duration, demand of terrain [45], experience level of the athlete [40], and altitude [46, 47], all, increase carbohydrate needs. It is not a concern of athletes' about consuming too much as almost all ultra-endurance walking and running events result in a deficit (as shown in Table 1) and narrowing the gap between energy intake and expenditure correlates positively with performance, rather it is a question of whether to pack carbohydrates or fat as the fuel source if they are carrying their own food. Fat provides more energy per gram and if the above variables are towards the lower end and less carbohydrate is needed, packing foods higher in fat will make the athletes carry load lighter and could allow them to narrow the energy gap further. This will be discussed in further detail in the section discussing dietary fat.

Current practices suggest that carbohydrate intakes in the diets of ultra-distance athletes range from 5 to $7 \mathrm{~g} / \mathrm{kg} /$ day in regular diets during training to $7-10 \mathrm{~g} /$ $\mathrm{kg} /$ day during the 3-4 days prior to competition [48]. A study by Mahon et al. [49] on mountain ultramarathon runners found that despite over $65 \%$ of athletes reporting that they intended to increase their $\mathrm{CHO}$ intake in the week prior to the event, no participants came close to their CHO-loading recommendations of $10-12 \mathrm{~g} / \mathrm{kg} / \mathrm{d}$ in the $48 \mathrm{~h}$ leading up to the event. This demonstrates that although a high carbohydrate intake is well known to benefit long duration endurance performance, athletes often fail to reach daily $\mathrm{CHO}$ targets needed to maximize glycogen storage due to the difficulty in practical application. As carbohydrate intakes both prior to and during ultra-endurance events with demanding characteristics of those discussed above are positively correlated with performance, athletes should strive to consume as close to this recommendation as possible if needed. Possible means of doing so is through frequent consumption of carbohydrate dense foods that are low in highly satiating nutrients, mainly being water, protein, and fiber [50], and high on the glycemic index. Examples include white rice, pretzels, breakfast cereals, bagels, and granola bars.

In addition, to restore glycogen stores between exercise sessions, a carbohydrate intake of $1.0-1.5 \mathrm{~g} / \mathrm{kg}$ at $2 \mathrm{~h}$ intervals for the first $6 \mathrm{~h}$ and beginning within the first $30 \mathrm{~min}$ following exercise appears to be an effective strategy for recovery [51]. Consumption of carbohydrates during performance has also been shown to be beneficial to best conserve muscle and hepatic glycogen storage and to maintain blood glucose concentration. A carbohydrate intake as high as $90 \mathrm{~g} / \mathrm{h}$ for the extensive duration of activities being discussed is suggested to maintain performance [43]. Again, however, this appears to have practical difficulties. Mahon et al. found that the average intake of the ultramarathon mountain runners was just $28 \mathrm{~g} / \mathrm{h}$. Another study on a $100 \mathrm{~km}$ ultra endurance running race found that mean intake was only $43 \mathrm{~g} / \mathrm{h}$. Again, narrowing the gap between energy intake and energy expenditure results in improvements in performance and athletes should strive to increase this $\mathrm{g} / \mathrm{h}$ intake. Some ways in which athletes may be able to achieve this is through fluids, gels, and even whole foods, depending on the athlete's preferences and gastrointestinal tolerance. Experimenting with different forms of carbohydrate in fluid replacement beverages such as glucose, maltose, fructose polymers, and branched chain starches with high glycemic indices at a concentration of $6-12 \%$ are recommended to provide carbohydrate late in exercise as muscle and liver glycogen stores become depleted and the risk of hypoglycemia is increased [52, 105]. These carbohydrates can also be provided in gel or bar form as it was recently demonstrated that carbohydrates in a beverage are oxidized at similar rates to carbohydrates from a gel [53] and from a bar [54]. Further ways to increase intake during events through management of gastrointestinal symptoms (GIS) will be discussed in the section on gastrointestinal intolerances.

\section{Fat}

Dietary fat is essential for optimal health and should not be overlooked by those engaging in ultra-endurance events. For those consuming a medium to high carbohydrate diet, a fat consumption similar to that recommended for the general population of $20-35 \%$ of energy intake is generally suggested to maintain performance and health [43]. Endurance training is known to enhance 
an athlete's capacity for fat oxidation during exercise and fat oxidation provides the greatest relative contribution to energy expenditure during low to moderate intensities of exercise with a peak recently shown to occur at $64 \pm 4 \%$ $\mathrm{VO}_{2} \max$ [55]. Recent research has explored ways in which this can be further up-regulated to enhance exercise capacity and sports performance by reducing the reliance on the muscles' limited glycogen stores and need to consume carbohydrate during prolonged events. Strategies employed to attain this include consuming a very low carbohydrate $(<50 \mathrm{~g} /$ day) high fat ( $>70 \%$ of energy consumption) diet for either scheduled periods or permanently [56]. After 2-3 weeks on this diet, the body is able to adapt to using fat at greater contributions, sparing more carbohydrate [57].

With a reduced reliance on carbohydrates as a fuel source as well as the elimination of the need to consume carbohydrates during activity, many potential advantages are presented. The athlete would no longer be required to carry sources of $\mathrm{CHO}$ with him or her, worry about attaining enough $\mathrm{CHO}$ or risk GIS from eating during activity. However, this strategy also comes at a cost. This reliance on fat limits the intensity of exercise that can be performed and severely restricts the capacity to do anaerobic work $[57,58]$. This is due to the decreased availability of $\mathrm{CHO}$ for glycolysis, the body's fastest energy producing mechanism for intense work.

In a study on mountain ultramarathon runners, Mahon et al. [49] found that those consuming suboptimal amounts of $\mathrm{CHO}$ had higher levels of blood $\beta$-ketones post-event and that these post-blood $\beta$-ketone levels were negatively associated with performance. This further supports the need for $\mathrm{CHO}$ intake during prolonged events, given that ketones are an indicator of fat metabolism, particularly if an objective is to complete the event in minimal time. It is also important to note that in non-fat adapted athletes low $\mathrm{CHO}$ availability increases muscle protein breakdown [59] and if performed chronically can lead to a loss of skeletal muscle mass. However, naturally during multi-day events, exercise pacing tends to conform to submaximal levels of intensity, often below lactate threshold to preserve limited glycogen stores and optimize fat utilization and the Krebs cycle pathway for ATP resynthesis [60]. This being said, fat adaptation is worth experimenting with for those who consume far below the recommended intakes of energy and carbohydrates for their events, particularly for those who are prone to GIS. Bringing calorie intake closer to energy expenditure using fat also improves performance when compared to a larger caloric deficit without extra fat [61, 62]. Since fat is more calorically dense than protein and carbohydrate, athletes who must carry their own food should choose high fat food options if it allows them to reach closer to their caloric needs over carbohydrate. Therefore, this strategy may be most appropriate for those competing in ultra-events which have breaks and which athletes must carry their own food.

Although preloading with dietary fat, specifically medium chain triglycerides (MCT), has strong literature support to potentially improve performance based on its capacity to serve as a fuel source and spare muscle glycogen $[63,64]$, the majority of studies have found no glycogen preserving effect or improvement in shorter distance endurance performance [65-70]. In longer duration activities, the research is conflicting. A study by Van Zyl et al. [193] found that performance in cyclists who rode for greater than $2 \mathrm{~h}$ in a $40 \mathrm{~km}$ simulated time trial had greater performance with supplemented beverages containing $\mathrm{CHO}+\mathrm{MCT}$ during the trial rather than either $\mathrm{CHO}$ or MCT alone. Contrary to this, Jeukendrup et al. [67] also studied long duration cycling activity (180 min) and found that the contribution to energy expenditure was small and did not provide any significant benefit to performance or carbohydrate preservation. The difference in the results of these two studies is likely due to the quantity of MCT ingested by the participants. Van Zyl et al. provided $86 \mathrm{~g}$ in total whereas Jeukendrup et al. provided $29 \mathrm{~g}$ in total. However, an intake of $86 \mathrm{~g}$ far exceeds the recommended maximum by many authors (30 g) who suggest intakes higher than this lead to gastrointestinal discomfort and diarrhea [71-73]. A later study by Jeukendrup et al. [74] attempted to test an intake of $85 \mathrm{~g}$ and found that it did indeed decrease performance due to provocation of GIS. At this time, the literature does not support the use of MCT supplementation in ultra-endurance activity.

\section{Protein}

Protein is a critical nutrient requiring considerable attention by the athlete to ensure proper recovery from exercise and to promote optimal adaptation between training sessions. The protein needs of athletes engaging in prolonged activity are greater than those required for the general population because of the need to repair damaged muscles and synthesize new muscle proteins. It further serves as an energy substrate during activity [75]. The repair and generation of body proteins greatly contribute to athletes' sought after adaptations to induced challenges and consequent improvements in performance.

Bodily protein stores have been shown to provide up to $10 \%$ of the total energy used during endurance exercises [76]. The fraction of contribution is influenced by many factors including intensity, duration and, as previously discussed, the level of glycogen/glucose availability in the body [76, 77]. When it comes to increased metabolic 
efficiency with training, a certain degree of metabolic efficiency does occur to mitigate amino acid oxidation with training [95], however, the rate of oxidation still increases over $2 \mathrm{~h}$ of endurance activity resulting in a several fold increase compared to resting conditions regardless of training level [96, 97]. Due to both the use of amino acids as a fuel source as well as muscle damage associated with exercise, skeletal muscle mass seems to decrease in ultraendurance running events without breaks, as has been shown in a few case reports of ultra-endurance athletes $[3,78]$. In contrast, in ultra-endurance events where there are breaks, skeletal muscle mass tends to remain stable [79-81]. When muscle loss occurs from walking or running, with the exception of the thigh, it has been shown to occur in all muscle groups with the greatest losses occurring in the lower leg or calf region $[3,82,83]$. The eccentric contractions involved in running cause the greater portion of body mass lost as muscle mass comparatively [82] to more concentric-based ultra-endurance activities such as cycling [84]. One way in which athletes may reduce the amount of endogenous protein lost, and by extension, promote recovery, is by ensuring adequate glycogen stores going into exercise and by consuming adequate energy during prolonged activity [35]. The following recommendations can also help ensure athletes are recovering lost muscle and preventing loss of skeletal muscle mass during training and events.

While a vast body of research supports a "hypertrophy-centric" view following resistance exercise, recent research highlights a critical role for dietary protein in supporting recovery from endurance exercise. Although the pre-eminent adaptations in resistance exercise compared to endurance exercise may be different, the requirements for amount, type, and timing are similar [75]. Protein remodeling, which is primarily determined by changes in muscle protein synthesis, is an important aspect of the acute recovery process after exercise that ultimately underpins the adaptations (e.g., greater muscle power, aerobic capacity) that accrue with endurance training [75]. Numerous studies have reported increases in mixed muscle protein synthesis following a single bout $[85,86]$ of exercise, and both short-term (i.e., 4 weeks) [87] and chronic (i.e., 4 months) [88] endurance training. Such increases in mixed muscle protein synthesis likely reflect enhanced remodeling of muscle proteins that may include mitochondrial-related proteins/enzymes, angiogenic proteins (e.g., endothelial and smooth muscle cells within capillaries), and myofibrillar proteins.

The current recommended intake of protein is 1.2$2.0 \mathrm{~g} / \mathrm{kg}$ for a general athletic population [45]. Given the extraordinary caloric needs to fuel these unique tasks, it is likely that these athletes are meeting and possibly exceeding this recommendation if they are meeting their energy requirements [76]. In addition to daily protein needs, other factors are also important for optimizing performance adaptations, including timing and partitioning of intake. To maximize protein synthesis, and thus muscle remodeling and recovery [89], it is suggested that endurance athletes consume a minimum of $20 \mathrm{~g}$ of protein at 3-4 h intervals to maximize muscle protein synthesis $[75,90]$. The amount required for ultra-endurance athletes and those who exercise longer than $2 \mathrm{~h}$ is presently unclear. However, it is likely that their needs would be even higher given the increase in total oxidation of amino acids during exercise as well as the possibility of splanchnic organ tissue damage due to the shunting of blood away from the digestive system during activity [91]. The rate of muscle breakdown is accelerated when muscle protein oxidation exceeds synthesis, which usually occurs in proportion to intensity and duration of the sporting activity [92-94].

Currently, ultra-endurance runners consume an approximate average of $12 \%$ of energy as protein during racing [98]. It has been posited that supplemental protein or amino acids on top of this intake during an ultra-run may improve performance through provision of amino acids for use as a fuel source and to attenuate muscle damage [99]. Despite the use of supplementary amino acids having been shown to improve performance and decrease muscle soreness in cyclists, a study on ultramarathon runners showed no benefits. Knechtle et al. [100] supplemented 14 subjects with $52.5 \mathrm{~g}$ of amino acids immediately before and during a $100 \mathrm{~km}$ run and compared them against a placebo group. Contrary to their hypothesis, there were no improvements in performance or effects on parameters related to skeletal muscle damage in the supplemented group. Unfortunately, measures of skeletal muscle damage were only taken immediately after the race. More research is needed to determine if the intake of amino acids during the race would lead to lower values of these markers in the following hours and days of recovery. Therefore, at the present time, evidence would suggest no additional benefit from consuming supplementary amino acids or protein during ultra-endurance running events.

In comparison to resistance exercisers, the immediacy of dietary protein intake after exercise is critical for optimal recovery [101, 102]. The consumption of a snack or meal with a minimum of $20 \mathrm{~g}$ of protein within $30-60$ min post exercise is suggested to optimally stimulate muscle protein synthesis and attenuate any existing breakdown that is ongoing from the bout of prolonged exercise [75]. 


\section{Hydration}

As little as a $2 \%$ reduction in body mass due to dehydration has been said to result in performance decrements as well as hemorheology, metabolic dysregulation, heat intolerance, and cardiovascular strain [103]. However, weight changes before and after an ultra-distance event do not provide an accurate indication of hydration status and weight loss greater than $2 \%$ does not necessarily have serious adverse consequences on performance [104]. Hoffman et al. [104] found that in addition to hydration status being unrelated to changes in weight, runners in a $161 \mathrm{~km}$ ultramarathon had a mean weight loss of approximately $3 \%$ and that many of the top performers had a weight loss of beyond $2 \%$ for much of the race. In other activities such as shorter duration endurance events, hydration needs for an event can be approximated during training through methods such as taking body weight before and after training at a duration, intensity, and environment that mimics that of a competition [105]. However, because reductions in body mass can be attributed to substantial breakdown of body tissues such as adipose and muscle [11] and increases in weight can result from reduced diuresis as well as decreases in intracellular osmolytes including glycogen, proteins, and triglycerides, this would be an ineffective strategy for ultra-endurance athletes. The reduced diuresis is induced by activation of vasopressin secretion and the angiotensin-renin-aldosterone mechanism during exercise and the decreases in intracellular osmolytes causes a shift of water to the extracellular compartment during very prolonged exercise [106]. With the complexity of hydration during these events, hyper-hydration has become increasingly common and is the most reported medical complication to occur during ultra-distance triathlons [107]. This is crucial as this can lead to the life-threatening case of hyponatremia by altering the blood serum to sodium ratio [108]. In fact, this shift appears to be a primary result of fluid overload and is unrelated to sodium losses [109]. To prevent over or underhydration, current available research suggests that the most suitable strategy to maintain hydration is to 'drink to thirst' $[15,27,104$, 109-112].

Urine color (see Fig. 1) can also be used to guide hydration in ultra-endurance running. However, it should be noted that urine concentration (i.e., color and osmolarity) rises substantially throughout the race and increasingly becomes less reliable with duration [15]. Costa et al. found that it is in fact less reliable than relying on thirst as an indicator of hydration status [15]. It is important to note here that substrate metabolism is also altered as a result of dehydration during exercise resulting in greater reliance on carbohydrate as a fuel source [113]. Although the fatigue associated with dehydration is mainly a result

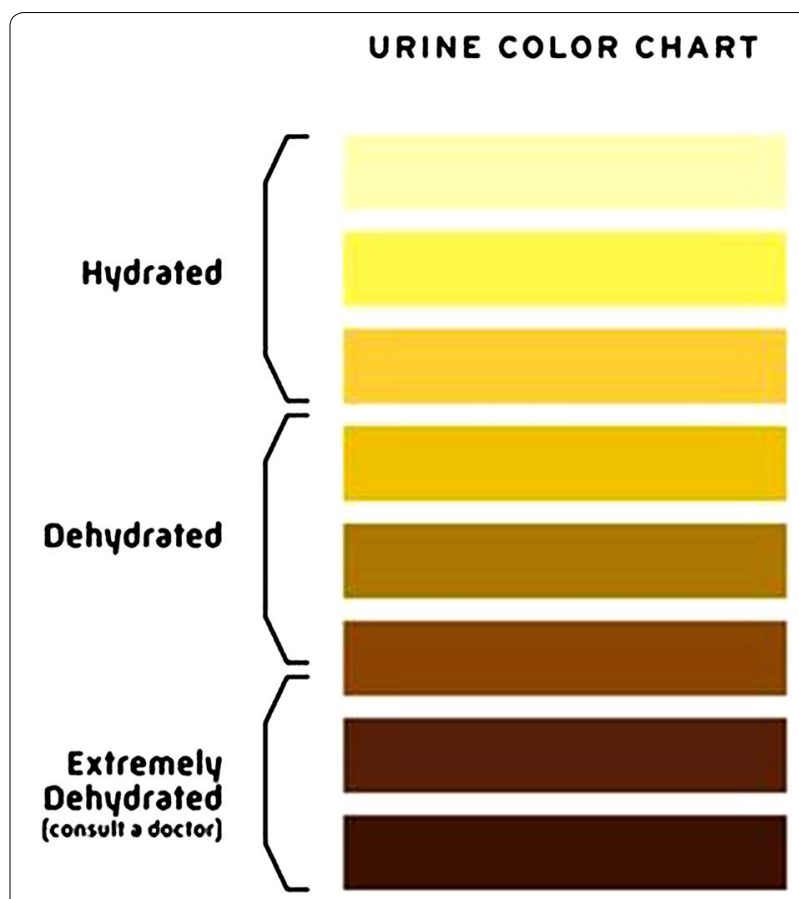

Fig. 1 Urine color as an indication of hydration status (reproduced with permission from [196])

of hyperthermia it also results in lower FFA uptake and higher muscle glycogen utilization [114]. Therefore, not only is maintaining hydration important for sustaining an optimal body temperature, preventing immediate fatigue, but it is also important to spare glycogen, potentially preventing or delaying later onset of fatigue.

Because sweat also contains sodium one might argue that sodium supplementation may be of importance during ultra-endurance walking and running events. Published data has shown that as high as $90-96 \%$ of ultraendurance runners use sodium supplements [27, 29, 104]. Although past recommendations suggest a sodium intake of $1.7-2.9 \mathrm{~g} / \mathrm{L}$ of fluid consumed to allow for fluid retention, more recent data have shown no benefit to hydration [19, 27-29, 104, 115] or blood serum sodium levels $[19,28,29,115]$ by consuming supplemental sodium during these races. This is likely due to the adaptations that increase sodium bioavailability and prevent losses (e.g. sweat, urine, and feces) which take place in response to periods of sodium deprivation or restriction [115-117]. In fact, sodium supplements taken in excess can result in inadequate weight loss and even unnecessary weight gain [118]. This ultimately results in fluid overload and decrements to performance as discussed above. It is therefore recommended that to best maintain hydration, athletes drink to thirst without using sodium supplementation beyond that taken in food and fluids, even when exercising in high ambient temperatures [104]. 
Other recommendations for maintaining euhydration during the event pertain to both the use of carbohydrate supplemented beverages and fluid intake before the event. As mentioned in the carbohydrate section, a concentration of $6-12 \%$ of carbohydrate is recommended for those that consume carbohydrate-supplemented beverages to achieve rapid absorption, reduce the risk of cramping, and provide energy [52, 105]. At $2-4 \mathrm{~h}$ prior to exercise, to achieve hydration balance going into the event, it is recommended to consume $5-10 \mathrm{~mL} / \mathrm{kg}$ body weight from water or carbohydrate-supplemented beverage. This will allow enough time for excretion of any excess as urine before the event allowing for a balanced bodily fluid level going into the activity [45].

\section{Vitamins and minerals}

Vitamin and mineral considerations are crucial when participating in and training for ultra-endurance activities. When it comes to athletic performance, these micronutrients are particularly important for energy production, hemoglobin synthesis, maintenance of bone health, adequate immune function, and protection of the body against oxidative damage. They also assist in important physiological processes related to synthesis, recovery, and adaptation to exercise. Because of this, exercise may increase the turnover and loss of these nutrients resulting in greater dietary intakes being required. Some vitamins and minerals that athletes need to pay particular attention to are calcium, vitamins D, C, E, and the B vitamins, iron, zinc, magnesium, as well as, beta carotene and selenium for their antioxidant properties.

Calcium and vitamin D play important roles in growth, maintenance, and repair of bone tissue as well as regulation of nerve conduction, and development and homeostasis in skeletal muscle. A deficiency in both or either calcium and vitamin D increases the risk of low bonemineral density and stress fractures [119]. Calcium can be obtained from food; however, vitamin D is mainly synthesized through sunlight. Serum Vitamin D levels should be tested regularly, especially in athletes who do not receive adequate sunlight daily, such as those who live at northern latitudes ( $>35$ th parallel) or who primarily train indoors throughout the year [120]. In those with suboptimal levels (stated in Table 2), supplementation may be necessary. Current vitamin D supplement recommendations suggest 1000-2000 IU per day for athletes [121].

B vitamins play a role in energy production and the building and repair of muscle tissue. There is some data suggesting that to obtain optimal health and performance, highly active athletes may need to double the current recommended amounts of these $B$ vitamins though it is likely that these needs are being met with increased
Table 2 Optimal serum levels for ultra-endurance runners/ walkers

\begin{tabular}{lll}
\hline Micronutrient & Serum marker & Optimal serum level \\
\hline Vitamin C & L-Ascorbic acid & $40-60 \mu \mathrm{M}$ \\
Calcium & Calcium & $4.5-5.5 \mathrm{mEq} / \mathrm{L}$ \\
Vitamin D & 25-hydroxyvitamin D & $75-100 \mathrm{nmol} / \mathrm{L}$ \\
Vitamin E & Alpha Tocopherol & $5.5-17 \mu \mathrm{g} / \mathrm{mL}$ \\
Folate & Plasma folate & $2.7-20 \mu \mathrm{g} / \mathrm{L}$ \\
Vitamin B12 & Holotranscobalamin & $35-156 \mathrm{pmol} / \mathrm{L}$ \\
Iron & Ferritin & $>50 \mathrm{ng} / \mathrm{mL}$ \\
Magnesium & Magnesium & $1.5-3.0 \mathrm{mEq} / \mathrm{L}$ \\
Zinc & Zinc & $84-159 \mu \mathrm{g} / \mathrm{dL}$ \\
\hline
\end{tabular}

energy intakes [122]. Of particular consideration, however, are vitamin B12 and folate. A deficiency in either of these nutrients results in anemia which can greatly reduce time to fatigue and therefore endurance performance [123]. Because vitamin B12 is obtained through animal products, such as meat and dairy, athletes such as vegetarians or vegans may need to consume supplements with this vitamin.

Iron deficiency will also result in anemia, reducing the ability of red blood cells to transport oxygen. A deficiency in iron is common among those engaged in prolonged activity due to up-regulation of the hormone hepcidin. The increase in this hormone is observed hours after exercise and reduces the gut's ability to absorb dietary iron [124]. Because of this, ultra-endurance athletes should pay particular attention to their iron consumption and obtain regular blood tests to check their ferritin status. Iron absorption can be improved by consuming heme iron found in meat products with non-heme iron found in plant products and vitamin $C$ with sources of iron $[125,126]$. Athletes should aim for blood ferritin levels of $>50 \mu \mathrm{g} / \mathrm{L}$ for optimal performance and iron supplements may be considered under the discretion of a health care provider if this level is not being met through dietary sources alone [127, 128].

Zinc plays a role in muscle repair, energy metabolism, and immune status. A deficiency in zinc can result in disrupted thyroid hormone levels, affecting metabolic rate and performance [129]. It can also reduce cardiorespiratory function, muscle strength, and endurance [123]. Athletes are at high risk of inadequate zinc levels [130] and should therefore strive to achieve adequate zinc intake through zinc-rich foods. They should be cautioned if using zinc supplements that they do not exceed the tolerable Upper Intake Level (UL) of zinc $(40 \mathrm{mg} /$ day) [131], which can lead to decreases in high-density lipoprotein cholesterol and nutrient imbalances by interfering with the bioavailability of other minerals such as 
iron and copper [123]. Zinc-rich foods include shellfish, green leafy vegetables, and seeds. If supplementation is required, athletes should receive guidance from their health care provider.

Magnesium supports the proper functioning of the nervous and musculoskeletal systems [132]. Deficiency can cause multiple symptoms resulting in decreased performance as it is linked to many pathological conditions of the cardiovascular, skeletal, and nervous systems [133]. Ultra-endurance athletes are at increased risk of this deficiency due to increased urinary and sweat losses induced by magnesium redistribution within the body during prolonged intense activity [134]. In addition, the dietary reference intake of $310-420 \mathrm{mg} /$ day is likely suboptimal for most athletes [135]. Ultra-endurance athletes should have their blood levels of magnesium tested regularly and self-monitor for common symptoms of hypomagnesaemia such as muscle cramps. Supplementation with magnesium is recommended if necessary and dosage should be determined under the discretion of their healthcare provider to avoid toxicity.

\section{Antioxidants}

Exercise can induce a release of free radicals or reactive oxygen species which have the ability to modify lipids, proteins, carbohydrates, and nucleic acids in the body [136]. These modifications are collectively known as oxidative damage or oxidative stress and have been linked to negative health outcomes such as insulin resistance, atherosclerosis, cardiac dysfunction, and injury [137]. Antioxidant vitamins and minerals, such as vitamins $C$ and $E$, beta carotene, and selenium can be used to mitigate these effects. These nutrients act in different ways to either remove oxidative species or prevent their reactions from happening [138]. However, because oxidative species also have some beneficial effects on the body, their function is not to completely eliminate these processes, but to keep them at homeostatic, and thus optimal, levels. Therefore, there is a threshold to which antioxidants can provide benefits for performance, health, and recovery. Research on ultra-endurance athletes has demonstrated that their need to prevent oxidative damage is higher given their extraordinary exercise volume [136].

Although more research is needed to examine the effects of these antioxidant supplements during and immediately prior to an event, current evidence suggests little to no benefit $[139,140]$. A study on runners ingesting vitamin supplements $(N=9)$ and mineral supplements $(N=12)$ showed that the supplementation did not result in faster race times compared to the athletes without supplemental intake of vitamins and minerals [141]. It is important to note that although ultra-endurance athletes may benefit from ample intakes of antioxidant vitamins and minerals that exceed the current recommendations for the general population, they should be cautioned not to consume these nutrients at levels above the ULs. High doses above the UL can also result in prooxidative effects, causing risks of decreased performance, recovery and health [142].

Other antioxidants which have recently been investigated for their effects on endurance performance include polyphenols with the most popularly researched being quercetin, catechins, and resveratrol. These polyphenols are organic chemical compounds mainly found in plants that have strong antioxidant properties [143]. They have also been shown to have anti-inflammatory, cardioprotection, and anti-carcinogenic properties in clinical populations [144]. However, few studies have investigated the effects of these polyphenols on performance, particularly in an ultra-endurance population.

Catechins are commonly found in plants such as green tea and cacao. Some human studies have shown positive effects for endurance including V02 max [145], fat oxidation, and insulin sensitivity [146] in an untrained population; however, studies on trained subjects are yet to show benefits [147-149]. It is unlikely that supplemental catechins would be beneficial to ultra-endurance performance.

Resveratrol is present in concentrated quantities in grapes. It's strong antioxidant properties have shown to be beneficial against degenerative and cardiovascular diseases from atherosclerosis, hypertension, ischemia/ reperfusion, heart failure, diabetes, obesity, aging, and neurodegenerative diseases [150]. With one exception, studies to date have only been performed on rodents, and the effects on performance range from extremely beneficial to extremely detrimental [151-157]. Taken together, these studies would suggest that resveratrol benefits trained rodents and is potentially harmful in untrained rodents. The only human study was performed in untrained elderly participants and the effect demonstrated that supplementation was also potentially harmful through blunting of cardiovascular training adaptations to endurance exercise [151]. Further research is needed before supplemental resveratrol should be taken by ultraendurance athletes.

Quercetin is found in foods such as red onion, dill, apples and capers and has been studied more extensively than other polyphenols. It provides many health benefits in humans [158] and has shown to encourage mitochondrial growth in rodents [159]. Although quercetin supplementation shows potential endurance performance benefits in cell culture and in vivo animal studies [160, 161], research on its use as a supplement in humans are less clear. Some studies have reported increased endurance exercise capacity and performance in humans 
following supplementation with quercetin [162-164]; however, many have failed to find benefits [165-171]. Of the 2 studies $[172,173]$ on ultra-endurance trained subjects, both have shown no significant benefit. Nieman et al. [172] examined the effect of quercetin supplementation on inflammation after three consecutive days of cycling and following an ultra-endurance run. No improvements in performance or attenuation of markers of muscle damage, inflammation, increases in plasma cytokines, and alterations in muscle cytokine mRNA expression were found [172]. Quindry et al. [173] supplemented half of their 63 ultra-endurance running trained subjects with quercetin combined with niacin and vitamin $C$ for 3 weeks leading up to and during a $160 \mathrm{~km}$ ultramarathon. The supplement did not fortify plasma antioxidant levels against ultramarathon-induced oxidative stress in blood plasma or improve performance. This being said, a 2011 meta analysis by Kressler et al. [194] encompassing the above research concluded that quercetin supplementation can improve human endurance exercise capacity in a small but significant magnitude $(\sim 3 \%)$. Based on data showing favorable outcomes for supplemental quercetin [162-164], a daily dosage of $1000 \mathrm{mg}$ could have small potential benefits and is unlikely to be detrimental for ultra-endurance trained populations.

Where micronutrients in general are concerned, there are currently no Recommended Dietary Allowance (RDA)'s in place specifically for athletes. However, the amounts needed in excess of those recommended for the general population are likely dependent on multiple factors including individual variability, training intensity, and training duration. To determine if ultra-endurance athletes are consuming adequate amounts of vitamins and minerals, they should obtain regular blood tests to ensure blood levels are being maintained at levels that are not only acceptable for general health but are optimal for performance (see Table 2). This may be particularly important during times when their training or nutrition changes. It is important to emphasize that regular adequate intake of vitamins and minerals is required for optimal performance and that consuming extra vitamins and minerals through supplementation immediately before or during an ultra-endurance event has not shown to provide any performance, health or recovery benefits $[141,174]$.

\section{Gastrointestinal intolerances}

During ultra-endurance activities and corresponding training exercises, food and fluid must be consumed while being active to minimize the energy deficit. Because of this, it is no surprise that GIS are a common issue for these athletes [175]. Endeavoring to prevent GIS is important as it is one of the most common cited reasons for inadequate intake during events $[176,177]$ and is positively correlated with increasing duration [178]. Running in particular appears to result in more pronounced GIS than other activities [175] as well as a dehydrated state compared with a euhydrated state [179]. There also seems to be an individual predisposition for GI distress during exercise as Pfieffer et al. have determined a positive relationship between GIS during races and history of GI issues both associated with and away from exercise $[175,180]$. Another common issue in ultraendurance athletes is reduced appetite, which is closely related to GIS as both are subsequent results of splanchnic ischemia. Particularly at workloads above $70 \% \mathrm{VO}_{2}$ max, splanchnic blood flow is reduced to about $30-40 \%$ as blood shifts to working muscles and skin to dissipate heat [177].

If the event has no enforced breaks, whole foods may not be an option as they may be too difficult to chew and swallow and could result in GIS. In this case, intake from fluids is a viable option as not only does it provide the energy but also hydration. However, in cases where the prevention of hyper-hydration is important, products such as sports gels can also be supplemented to the racer's diet. With gels, it has been shown that high doses of $\mathrm{CHO}(1.4 \mathrm{~g} / \mathrm{min})$ are well tolerated by most runners [180]. Against this background, it may be best to determine strategies, such as use of different types of nutritional sources and frequency of consumption to find which methods work best to maximize carbohydrate intake during an event without causing GI distress. One of the possible ways that this could be done is through coingestion of glucose and fructose as a carbohydrate source rather than one or the other. Research suggests that this can increase carbohydrate oxidation from an average of $1-1.26 \mathrm{~g} / \mathrm{min}$ mainly due to increased bioavailability as the 2 different compounds use different transporters within the gut [181]. With the use of gels as a source of carbohydrates, Pfeiffer et al. [180] showed no overall difference in tolerance between glucose-based gels and combined glucose and fructose gels. However, some individuals showed more symptoms with one or the other gel. It should, therefore, be advised that individual athletes, especially those who experience GI problems frequently, test their tolerance during intense training sessions, ideally under conditions similar to those of the races they aim to compete in.

The intake of the nutrients fat, fiber, and protein, have all been linked to GIS during exercise [182]. To prevent this, food items low in these nutrients, such as bananas, biscuits, energy gels/bars, and sports drinks, are popular food and fluid choices for ultra-endurance events. However, as the duration of ultra-endurance races increases, 
these food and drink choices have become less tolerable and appealing $[183,184]$. In terms of athletes' tolerance, individual testing of food and drink intake during training conditions similar to the event they are training for are vital. No matter where the athlete is starting from, another potential strategy is "gut training", which involves increasing the absorptive capacity of the gut through high carbohydrate dieting and progressively increasing the hourly carbohydrate intake during training [185]. Although the evidence of this is mainly anecdotal, intestinal carbohydrate transporters can indeed be up-regulated $[186,187]$ and gastric emptying rates can be enhanced with training [188].

GIS occur less frequently after adequate training or when relative exercise intensity is reduced $[189,190]$. Although more research in this area is needed, experimentation with this strategy during training is likely to present little risk and athletes should dedicate at least some time to gut training. Endurance training itself appears to enhance gastric transit time [191], and higher energy intakes during training further enhance this rate [192]. Cox et al. [187] demonstrated that exogenous carbohydrate oxidation rates were higher after the high carbohydrate diet $(6.5 ; 1.5 \mathrm{~g} / \mathrm{kg}$ BW provided mainly as a carbohydrate supplement during training) for 28 days compared with a control diet ( $5 \mathrm{~g} / \mathrm{kg} \mathrm{BW} /$ day) in endurance trained cyclists. The higher rates were attributed to improved absorption, which provides evidence that the gut is indeed adaptable and that this could be used as a practical method to increase exogenous carbohydrate oxidation. Therefore, ultra-endurance runners should strive to gradually increase their intakes as tolerated during training to further approach suggested intakes (kcals/ $\mathrm{km}$ ) for events. This could lead to improvements in performance through greater fuel availability as discussed in preceding sections.

\section{Conclusion}

There is a paucity of agreed-on and concrete nutrition best practices for ultraendurance runners and even less demarcating such by event type. From a macronutrients perspective, ultra-endurance athletes need to ensure adequate intake. Generally, carbohydrate, protein, and fat recommendations are $8-12 \mathrm{~g}$ of $\mathrm{CHO} / \mathrm{kg}$ body weight/day, $\geq 20 \mathrm{~g}$ at $3-4 \mathrm{~h}$ intervals and $20-35 \%$ of energy intake, respectively, and athletes should strive to minimize the gap between energy intake and energy expenditure to optimize performance. However, the practicality of such recommendations needs to be considered on an individual basis and the importance of rehearsal of an individualized nutrition strategy prior to competition cannot be overemphasized. Because micronutrients are crucial and may sometimes be overlooked, special attention needs to be placed on each both in terms of interaction with the body's internal physiology, other ingested foods and the nature and intensity of physical rigor the body endures. As far as is necessary, and in keeping with advice from healthcare providers, ultra-endurance athletes may use supplements to support training and events performance and aid in recovery. While some recommendations presented are prescriptive in nature based on the findings of various studies, ultra-endurance athletes are encouraged to apply them within the context of their particular training regiment, body mass composition, and corresponding physiological needs. All the literature reviewed indicate that ultraendurance athletes must take great care in attending to their nutritional needs to maintain good health, promote optimal performance, and reduce the likelihood of injuries. Proper nutrition will result in decreased energy depletion, better performance, and accelerated recovery. With the growing international appeal of ultra-endurance events, significant research is needed to promote the health and wellbeing of athletes. More longitudinal studies are needed to ascertain the precise nutritional and environmental conditions under which athletes perform most optimally based on age, gender, type of event, body type, and other physiological factors.

\section{Abbreviations}

BMR: basal metabolic rate; $\mathrm{CHO}$ : carbohydrates; UL: upper intake level; RDA: recommended dietary allowance; GIS: gastrointestinal symptoms; ATP: adensosine triphospate.

\section{Acknowledgements}

The author wishes to thank the US Anti-doping Agency for their permission to use Fig. 1 and my professor, Dr. Greg Wells, for his constructive feedback and encouragement to publish this review.

\section{Competing interests}

The authors declare no competing interests.

Received: 4 June 2016 Accepted: 1 November 2016 Published online: 21 November 2016

\footnotetext{
References

1. Knechtle B. Nutrition in ultra-endurance racing-aspects of energy balance, fluid balance and exercise-associated hyponatremia. Medicina Sportiva. 2013;17:200

2. Brown JS, Connolly DA. Selected human physiological responses during extreme heat: the badwater ultramarathon. J Strength Cond Res. 2015;29(6):1729-36.

3. Bircher S, Enggist A, Jehle T, Knechtle B. Effects of an extreme endurance race on energy balance and body composition - a case study. J Sports Sci Med. 2006;5(1):154-62.

4. Knechtle B, Bisig A, Schlapfer F, Zwyssig D. Energy metabolism in long-term endurance sports: a case study. Praxis. 2003;92:8592003. doi:10.1024/0369-8394.92.18.859.

5. Knechtle B, Zimmermann K, Wirth A, Knechtle P, Kohler G. 12 hours running results in a decrease of the subcutaneous adipose tissue. Praxis. 2007:96:1423-9. doi:10.1024/1661-8157.96.38.1423.
} 
6. Hulton AT, Lahart I, Williams KL, Godfrey R, Charlesworth S, Wilson M, Whyte G. Energy expenditure in the race across america (RAAM). Int J Sports Med. 2010;31:463-7. doi:10.1055/s-0030-1251992.

7. Kruseman M, Bucher S, Bovard M, Kayser B, Bovier PA. Nutrient intake and performance during a mountain marathon: an observational study. Eur J Appl Psychol. 2005;94(1-2):151-7.

8. Glace BW, Murphy CA, McHugh MP. Food intake and electrolyte status of ultramarathoners competing in extreme heat. J Am Coll Nutr. 2002;21(6):553-9.

9. Dempster S, Britton R, Murray A, Costa RJ. Case study: nutrition and hydration status during $4,254 \mathrm{~km}$ of running over 78 consecutive days. Int J Sport Nutr Exerc Metab. 2013;23(5):533-41.

10. Clemente-Suarez VJ. Psychophysiological response and energy balance during a 14-h ultraendurance mountain running event. Appl Physiol Nutr Metab. 2015. doi:10.1139/apnm-2014-0263.

11. Paulin S, Roberts J, Roberts M, Davis I. A case study evaluation of competitors undertaking an antarctic ultra-endurance event: nutrition, hydration and body composition variables. Extrem Physiol Med. 2015;4:3.

12. Hill RJ, Davies PS. Energy expenditure during 2 week of an ultra-endurance run around Australia. Med Sci Sports Exerc. 2001;33(1):148-51.

13. Koehler K, Huelsemann F, de Marees M, Braunstein B, Braun H, Schaenzer W. Case study: simulated and real-life energy expenditure during a 3-week expedition. Int J Sport Nutr Exerc Metab. 2011;21(6):520-6.

14. Costa RJ, Gill SK, Hankey J, Wright A, Marczak S. Perturbed energy balance and hydration status in ultra-endurance runners during a $24 \mathrm{~h}$ ultra-marathon. Br J Nutr. 2014;112(3):428-37.

15. Costa RJ, Teixeira A, Rama L, Swancott AJ, Hardy LD, Lee B, CamõesCosta V, Gill S, Waterman JP, Freeth EC, Barrett E, Hankey J, Marczak S, Valero-Burgos E, Scheer V, Thake CD. Water and sodium intake habits and status of ultra-endurance runners during a multi-stage ultra-marathon conducted in a hot ambient environment: an observational field based study. Nutr J. 2013:12-13.

16. O'Hara WJ, Allen C, Shephard RJ, Gill JW. LaTulippe-a case study of a one hundred and sixty kilometre runner. Br J Sports Med. 1977;11(2):83-7.

17. Knechtle B, Senn O, Imoberdorf R, Joleska I, Wirth A, Knechtle P, Rosemann T. Maintained total body water content and serum sodium concentrations despite body mass loss in female ultra-runners drinking ad libitum during a 100 km race. Asia Pac J Clinl Nutr. 2010;19(1):83-90.

18. Kimber NE, Ross JJ, Mason SL, Speedy DB. Energy balance during an ironman triathlon in male and female triathletes. Int J Sport Nutr Exerc Metab. 2002;12(1):47-62.

19. Hew-Butler TD, Sharwood K, Collins M, Speedy D, Noakes T. Sodium supplementation is not required to maintain serum sodium concentrations during an ironman triathlon. Br J Sports Med. 2006;40(3):255-9.

20. Knechtle B, Senn O, Imoberdorf R, Joleska I, Wirth A, Knechtle P, Rosemann T. No fluid overload in male ultra-runners during a $100 \mathrm{~km}$ ultra-run. Res Sports Med. 2011. doi:10.1080/15438627.2010.510039.

21. Eden $B D$, Abernethy PJ. Nutritional intake during an ultraendurance running race. Int J Sport Nutr. 1994;4(2):166-74.

22. McCubbin AJ, Cox GR, Broad EM. Case study: nutrition planning and intake for marathon des sables-a series of five runners. Int I Sport Nutr Exerc Metab. 2016.

23. Edwards JE, Lindeman AK, Mikesky AE, Stager JM. Energy balance in highly trained female endurance runners. Med Sci Sports Exerc. 1993:25(12):1398-404.

24. Stuempfle KJ, Hoffman MD, Weschler LB, Rogers IR, Hew-Butler T. Race diet of finishers and non-finishers in a 100 mile $(161 \mathrm{~km})$ mountain footrace. J Am Coll Nutr. 2011;30(6):529-35.

25. Knechtle B, Knechtle P, Rust CA, Rosemann T, Lepers R. Finishers and nonfinishers in the 'swiss cycling marathon' to qualify for the 'race across America'. J Strength Cond Res. 2011;25:3257-63. doi:10.1519/ JSC.0b013e31821606b3.

26. Costa RJ, Snipe R, Camoes-Costa V, Scheer V, Murray A. The impact of gastrointestinal symptoms and dermatological injuries on nutritional intake and hydration status during ultramarathon events. Sports Med. 2016. doi:10.1186/s40798-015-0041-9.

27. Hoffman MD, Stuempfle KJ. Is sodium supplementation necessary to avoid dehydration during prolonged exercise in the heat? J Strength Cond Res. 2016;30:615-20. doi:10.1519/JSC.00000000000001138.
28. Hoffman MD, Stuempfle KJ. Sodium supplementation and exerciseassociated hyponatremia during prolonged exercise. Med Sci Sports Exerc. 2015:47(9):1781-7.

29. Winger JM, Hoffman MD, Hew-Butler TD, Stuempfle KJ, Dugas JP, Fogard K, Dugas LR. The effect of physiology and hydration beliefs on race behavior and postrace sodium in $161-\mathrm{km}$ ultramarathon finishers. Int J Sports Physiol Perform. 2013;8(5):536-41.

30. Singh A, Pelletier PA, Deuster PA. Dietary requirements for ultra-endurance exercise. Sports Med. 1994;18(5):301-8.

31. Hoffman MD, Pasternak A, Rogers IR, Khodaee M, Hill JC, Townes DA, Scheer B, Krabak BJ, Basset P, Lipman GS. Medical services at ultraendurance foot races in remote environments: medical issues and consensus guidelines. Sports Med. 2014;44(8):1055-69.

32. Scheer BV, Murray A. Al Andalus ultra trail: an observation of medical interventions during a 219-km, 5-day ultramarathon stage race. Clin J Sport Med. 2011;21(5):444-6.

33. Ramos-Campo DJ, Avila-Gandia V, Alacid F, Soto-Mendez F, Alcaraz PE, Lopez-Roman FJ, Rubio-Arias JA. Muscle damage, physiological changes, and energy balance in ultra-endurance mountain-event athletes. Appl Physiol Nutr Metab. 2016. doi:10.1139/apnm-2016-0093.

34. Fallon KE, Broad E, Thompson MW, Reull PA. Nutritional and fluid intake in a 100-km ultramarathon. Int J Sport Nutr. 1998:8(1):24-35.

35. StellingwerffT. Contemporary nutrition approaches to optimize elite marathon performance. Int J Sports Physiol Perform. 2013;8(5):573-8.

36. Hoffman MD, Hew-Butler T, Stuempfle KJ. Exercise-associated hyponatremia and hydration status in 161-km ultramarathoners. Med Sci Sports Exerc. 2013:45:784-91. doi:10.1249/MSS.0b013e31827985a8.

37. Khodaee M, Ansari M. Common ultramarathon injuries and illnesses: race day management. Current Sports Med Rep. 2012. doi:10.1249/ JSR.0b013e318272c34b.

38. Clark N, Tobin J Jr, Ellis C. Feeding the ultraendurance athlete: practical tips and a case study. J Am Diet Assoc. 1992;92(10):1258-62.

39. Essén B. Intramuscular substrate utilization during prolonged exercise. Ann NY Acad Sci. 1977;301:30-44.

40. O'brien MJ, Viquie CA, Mazzeo RS, Brooks GA. Carbohydrate dependence during marathon running. Med Sci Sports Exerc 1993:25(9):1009-17.

41. Coyle EF, Coggan AR, Hemmert MK, Ivy JL. Muscle glycogen utilization during prolonged strenuous exercise when fed carbohydrate. J Appl Physiol. 1985;61(1):165-72.

42. Ørtenblad N, Westerblad H, Nielsen J. Muscle glycogen stores and fatique. J Physiol. 2013;591(18):4405-13.

43. Burke LM, Kiens B, Ivy JL. Carbohydrates and fat for training and recovery. J Sports Sci. 2004;22(1):15-30.

44. Burke LM, Hawley JA. Carbohydrate and exercise. Curr Opin Clin Nutr Metab Care. 1999;2(6):515-20.

45. Thomas DT, Erdman KA, Burke LM. Position of the academy of nutrition and dietetics, Dietitians of Canada, and the American College of Sports Medicine: nutrition and athletic performance. J Acad Nutr Diet. 2016;116(3):501-28.

46. Consolazio CF, Matoush LO, Johnson HL, Krzywicki HJ, Daws TA, Isaac GJ. Effects of high-carbohydrate diets on performance and clinical symptomatology after rapid ascent to high altitude. Fed Proc. 1969;28(3):9347-943.

47. Oliver SJ, Golja P, Macdonald JH. Carbohydrate supplementation and exercise performance at high altitude: a randomized controlled trial. High Alt Med Biol. 2012;13(1):22-31.

48. Burke LM, Cox GR, Culmmings NK, Desbrow B. Guidelines for daily carbohydrate intake: do athletes achieve them? Sports Med. 2001:31(4):267-99.

49. Mahon E, Hackett A, Stott T, George K, Davies I. Macronutrient consumption prior to, and during, a mountain marathon. Am J Sports Sci. 2014;2(1):5-12.

50. Drewnowski A. Energy density, palatability, and satiety: implications for weight control. Nutr Rev. 1998;56(12):347-53.

51. Ivy JL, Katz AL, Cutler CL, Sherman WM, Coyle EF. Muscle glycogen synthesis after exercise: effect of time of carbohydrate ingestion. J Appl Physiol. 1985;64(4):1480-5.

52. Saris WH, van Erp-Baart MA, Brouns F, Westerterp KR, Hoor F. Study on food intake and energy expenditure during extreme sustained exercise: the tour de france. Int J Sports Med. 1989;10(Suppl 1):S26-31. 
53. Pfeiffer $B$, Stellingwerff T, Zaltas $E$, Jeukendrup AE. CHO oxidation from a $\mathrm{CHO}$ gel compared with a drink during exercise. Med Sci Sports Exerc. 2010:42:2038-45. doi:10.1249/MSS.0b013e3181e0efe6.

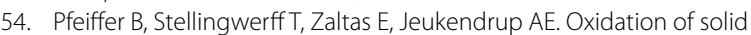
versus liquid CHO sources during exercise. Med Sci Sports Exerc. 2010 doi:10.1249/MSS.0b013e3181e0efc9.

55. Achten J, Gleeson M, Jeukendrup AE. Determination of the exercise intensity that elicits maximal fat oxidation. Med Sci Sports Exerc. 2002;34(1):92-7.

56. Burke LM. Re-examining high-fat diets for sports performance: did we call the 'nail in the coffin' too soon? Sports Medicine. 2015:45(1):33-49.

57. Volek JS, Noakes T, Phinney SD. Rethinking fat as a fuel for endurance exercise. Eur J Sport Sci. 2015;15(1):13-20.

58. Phinney SD, Bistrian BR, Evans WJ, Gervino E, Blackburn GL. The human metabolic response to chronic ketosis without caloric restriction: preservation of submaximal exercise capability with reduced carbohydrate oxidation. Metab Clin Exp. 1983;32(8):769-76.

59. Howarth KR, Phillips SM, Macdonald MJ, Richards D, Moreau NA Gibala MJ. Effect of glycogen availability on human skeletal muscle protein turnover during exercise and recovery. J Appl Physiol. 1985;109(2):431-8.

60. Jeukendrup A, Gleeson M. Vitamins and minerals. In: Bahrke MS, editor. Sport nutrition: an introduction to energy production and performance. London: Human Kinetics; 2010. p. 221-52.

61. Pendergast DR, Leddy JJ, Venkatraman JT. A perspective on fat intake in athletes. J Am Coll Nutr. 2000;19(3):345-50.

62. Horvath PJ, Besch SR, Kilanowski C, Leddy J, Pendergast DR. Endurance of male college age long distance runners with energy supplementation using peanuts or a high carbohydrate energy bar. Am Coll of Nutr. 1998:98.

63. Rennie MJ, Winder WW, Holloszy JO. A sparing effect of increased plasma fatty acids on muscle and liver glycogen content in the exercising rat. Biochem J. 1976;156(3):647-55.

64. Clegg ME. Medium-chain triglycerides are advantageous in promoting weight loss although not beneficial to exercise performance. Int J Food Sci Nutr. 2010;61:653-79. doi:10.3109/09637481003702114.

65. Angus DJ, Hargreaves M, Dancey J, Febbraio MA. Effect of carbohydrate or carbohydrate plus medium-chain triglyceride ingestion on cycling time trial performance. J Appl Physiol. 2000;88(1):113-9.

66. Horowitz JF, Mora-Rodriguez R, Byerley LO, Coyle EF. Preexercise medium-chain triglyceride ingestion does not alter muscle glycogen use during exercise. J Appl Physiol. 2000;88(1):219-25.

67. Jeukendrup AE, Saris WH, Brouns F, Halliday D, Wagenmakers JM. Effects of carbohydrate $(\mathrm{CHO})$ and fat supplementation on $\mathrm{CHO}$ metabolism during prolonged exercise. Metab Clin Exp. 1996;45(7):915-21.

68. Misell LM, Lagomarcino ND, Schuster V, Kern M. Chronic medium-chain triacylglycerol consumption and endurance performance in trained runners. J Sports Med Phys Fitness. 2001;41(2):210-5.

69. Goedecke JH, Clark VR, Noakes TD, Lambert EV. The effects of mediumchain triacylglycerol and carbohydrate ingestion on ultra-endurance exercise performance. Int J Sport Nutr Exerc Metab. 2005;15(1):15-27.

70. Vistisen B, Nybo L, Xu X, Hoy CE, Kiens B. Minor amounts of plasma medium-chain fatty acids and no improved time trial performance after consuming lipids. J Appl Physiol. 2003;95(6):2434-43.

71. Williams MH. The ergogenics edge. Champaign: Human Kinetics; 1998.

72. Jeukendrup AE, Saris WH, Wagenmakers AJ. Fat metabolism during exercise: a review-part III: effects of nutritional interventions. Int J Sports Med. 1998;19:371-9. doi:10.1055/s-2007-971932.

73. Graham TE. The importance of carbohydrate, fat and protein for the endurance athlete. In: Shephard RJ, Astrand PO, editors. Endurance in sport. Oxford: Blackwell Science; 2000. p. 197-207.

74. Jeukendrup AE, Thielen JJ, Wagenmakers AJ, Brouns F, Saris WH. Effect of medium-chain triacylglycerol and carbohydrate ingestion during exercise on substrate utilization and subsequent cycling performance. Am J Clin Nutr. 1998;67(3):397-404.

75. Moore DR, Camera DM, Areta JL, Hawley JA. Beyond muscle hypertrophy: why dietary protein is important for endurance athletes. Appl Physiol Nutr Metab. 2014;39(9):987-97.

76. Tarnopolsky M. Protein requirements for endurance athletes. Nutrition. 2004;20(7-8):662-8.
77. Lemon PW, Mullin JP. Effect of initial muscle glycogen levels on protein catabolism during exercise. J Appl Physiol. 1980;48(4):624-9.

78. Knechtle B, Bircher S. Changes in body composition during an extreme endurance run. Praxis. 2005;94:371-7. doi:10.1024/0369-8394.94.10.371.

79. Cox C, Gaskill S, Ruby B, Uhlig S. Case study of training, fitness, and nourishment of a dog driver during the iditarod 1049-mile dogsled race. Int J Sport Nutr Exerc Metab. 2003;13(3):286-93.

80. Frykman PN, Harman EA, Opstad PK, Hoyt RW, DeLany JP, Friedl KE. Effects of a 3-month endurance event on physical performance and body composition: the $\mathrm{G} 2$ trans-greenland expedition. Wilderness Environ Med. 2003;14(4):240-8.

81. Reynolds RD, Lickteig JA, Deuster PA, Howard MP, Conway JM, Pietersma A, Deurenberg P. Energy metabolism increases and regional body fat decreases while regional muscle mass is spared in humans climbing mt. everest. J Nutr. 1999;129(7):1307-14.

82. Knechtle B, Kohler G. Running 338 kilometres within five days has no effect on body mass and body fat but reduces skeletal muscle massthe isarrun 2006. J Sports Sci Med. 2007:6(4):401-7.

83. Raschka C, Plath M, Cerull R, Bernhard W, Jung K, Leitzmann C. The body muscle compartment and its relationship to food absorption and blood chemistry during an extreme endurance performance. Zeitschrift fur Ernahrungswissenschaft. 1991;30(4):276-88.

84. Knechtle B, Duff B, Amtmann G, Kohler G. An ultratriathlon leads to a decrease of body fat and skeletal muscle mass-the triple iron Triathlon Austria 2006. Res Sports Med. 2008. doi:10.1080/15438620701878881.

85. Harber MP, Konopka AR, Jemiolo B, Trappe SW, Trappe TA, Reidy PT. Muscle protein synthesis and gene expression during recovery from aerobic exercise in the fasted and fed states. Am J Physiol Regul Integr Comp Physiol. 2010;299:R1254-62.

86. Mascher H, Ekblom B, Rooyackers O, Blomstrand E. Enhanced rates of muscle protein synthesis and elevated mTOR signalling following endurance exercise in human subjects. Acta Physiol. 2011:202:175-84

87. Pikosky MA, Gaine PC, Martin WF, Grabarz KC, Ferrando AA, Wolfe RR, Rodriguez NR. Aerobic exercise training increases skeletal muscle protein turnover in healthy adults at rest. J Nutr. 2006;136(2):379-83.

88. Short KR, Vittone JL, Bigelow ML, Proctor DN, Nair KS. Age and aerobic exercise training effects on whole body and muscle protein metabolism. Am J Physiol Endocrinol Metab. 2004;286:E92-101.

89. Churchward-Venne TA, Burd NA, Phillips SM. Nutritional regulation of muscle protein synthesis with resistance exercise: strategies to enhance anabolism. Nutr Metab. 2012;9(1):40.

90. Moore DR, Areta J, Coffey VG, StellingwerffT, Phillips SM, Burke LM, Cléroux M, Godin JP, Hawley JA. Daytime pattern of post-exercise protein intake affects whole-body protein turnover in resistance-trained males. Nutr Metab. 2012;9(1):1

91. Van Wijck K, Lenaerts K, Van Loon LJ, Peters WH, Buurman WA, Dejong $\mathrm{CH}$. Exercise-induced splanchnic hypoperfusion results in gut dysfunction in healthy men. PLoS One. 2011;6(7):e22366.

92. Stroud MA, Jackson AA, Waterlow JC. Protein turnover rates of two human subjects during an unassisted crossing of antarctica. $\mathrm{Br} J$ Nutr. 1996

93. Lemon PW, Nagle FJ. Effects of exercise on protein and amino acid metabolism. Med Sci Sports Exerc. 1981;13(3):141-9.

94. Norton LE, Layman DK. Leucine regulates translation initiation of protein synthesis in skeletal muscle after exercise. J Nutr. 2006;136(2):533S-7S.

95. McKenzie S, Phillips SM, Carter SL, Lowther S, Gibala MJ, Tarnopolsky MA. Endurance exercise training attenuates leucine oxidation and BCOAD activation during exercise in humans. Am J Physiol. 2000;278(4):E580-7

96. Miller SL, Gaine PC, Maresh CM, Armstrong LE, Ebbeling CB, Lamont LS, Rodriguez NR. The effects of nutritional supplementation throughout an endurance run on leucine kinetics during recovery. Int J Sport Nutr Exerc Metab. 2007;17(5):456-67.

97. Koopman R, Pannemans DL, Jeukendrup AE, Gijsen AP, Senden JM, Halliday D, Wagenmakers AJ. Combined ingestion of protein and carbohydrate improves protein balance during ultra-endurance exercise. Am J Physiol-Endocrinol Metab. 2004;287:E712-20. doi:10.1152/ ajpendo.00543.2003. 
98. Knechtle B. Nutrition in ultra-endurance racing - aspects of energy balance, fluid balance and exercise associated hyponatremia. Medicina Sportiva. 2013;17(4):200-10

99. Dohm GL, Tapscott EB, Kasperek GJ. Protein degradation during endurance exercise and recovery. Med Sci Sports Exerc. 1987;19(Suppl 5):S166-71.

100. Knechtle B, Knechtle P, Mrazek C, Senn O, Rosemann T, Imoberdorf $R$, Ballmer P. No effect of short-term amino acid supplementation on variables related to skeletal muscle damage in $100 \mathrm{~km}$ ultrarunners - a randomized controlled trial. J Int Soc Sports Nutr. 2011. doi:10.1186/1550-2783-8-6.

101. Burd NA, West DW, Moore DR, Atherton PJ, Staples AW, Prior T, Tang JE, Rennie MJ, Baker SK, Phillips SM. Enhanced amino acid sensitivity of myofibrillar protein synthesis persists for up to $24 \mathrm{~h}$ after resistance exercise in young men. J Nutr. 2011;141(4):568-73.

102. Levenhagen DK, Gresham JD, Carlson MG, Maron DJ, Borel MJ, Flakoll PJ. Postexercise nutrient intake timing in humans is critical to recovery of leg glucose and protein homeostasis. Am J Physiol Endocrinol Metab. 2001;280(6):E982-93.

103. Goulet ED. Effect of exercise-induced dehydration on endurance performance: evaluating the impact of exercise protocols on outcomes using a meta-analytic procedure. Br J Sports Med. 2013;47(11):679-86.

104. Hoffman MD, Stuempfle KJ. Hydration strategies, weight change and performance in a $161 \mathrm{~km}$ ultramarathon. Res Sports Med. 2014. doi:10.1 080/15438627.2014.915838

105. American College of Sports Medicine, Armstrong LE, Casa DJ, MillardStafford M, Moran DS, Pyne SW, Roberts WO, American College of Sports Medicine position stand. Exertional heat illness during training and competition. Med Sci Sports Exerc. 2007;39(3):556-72.

106. Rehrer NJ. Fluid and electrolyte balance in ultra-endurance sport. Sports Med. 2001;31(10):701-15.

107. Speedy DB, Noakes TD, Schneider C. Exercise-associated hyponatremia: a review. Emerg Med. 2001;13(1):17-27.

108. Noakes T, Norman RJ, Buck RH, Goldonton J, Stevenson K, Pittaway D. The incidence of hyponatremia during prolonged ultraendurance exercise. Med Sci Sports Exerc. 1990;22(2):165-70.

109. Noakes TD, Speedy DB. Case proven: exercise associated hyponatraemia is due to overdrinking. so why did it take 20 years before the original evidence was accepted? Br J Sports Med. 2006;40(7):567-72.

110. Noakes T. International Marathon Medical Directors Association (IMMDA): fluid replacement during marathon running. Clin J Sport Med. 2003;13(5):309-18.

111. Getzin AR, Milner C, LaFace KM. Nutrition update for the ultraendurance athlete. Curr Sports Med Rep. 2011. doi:10.1249/JSR.0b013e318237fcdf.

112. Bennett BL, Hew-Butler T, Hoffman MD, Rogers IR, Rosner MH, Wilderness Medical Society. Wilderness medical society practice guidelines for treatment of exercise-associated hyponatremia. Wilderness Environ Med. 2013;24(3):228-40.

113. Hargreaves M, Dillo P, Angus D, Febbraio M. Effect of fluid ingestion on muscle metabolism during prolonged exercise. J Appl Physiol. 1996;80(1):363-6.

114. Gonzalez-Alonso J, Calbet JA, Nielsen B. Metabolic and thermodynamic responses to dehydration-induced reductions in muscle blood flow in exercising humans. J Physiol. 1999;2:577-89.

115. Speedy DB, Thompson JM, Rodgers I, Collins M, Sharwood K, Noakes TD. Oral salt supplementation during ultradistance exercise. Clin J Sport Med. 2002;12(5):279-84.

116. Hew-Butler T, Ayus JC, Kipps C, Maughan RJ, Mettler S, Meeuwisse WH, Wharam P. Statement of the second international exercise-associated hyponatremia consensus development conference, New Zealand, 2007. Clin J Sport Med. 2008;18:111-21. doi:10.1097/JSM.0b013e318168ff31.

117. Hew-Butler T, Verbalis JG, Noakes TD, International Marathon Medical Directors Association. Updated fluid recommendation: position statement from the international marathon medical directors association (IMMDA). Clin J Sport Med. 2006;16(4):283-92.

118. Luks AM, Robertson HT, Swenson ER. An ultracyclist with pulmonary edema during the bicycle race across america. Med Sci Sports Exerc. 2007:39:8. doi:10.1249/01.mss.0000235885.79110.79.

119. Morgan KT. Nutritional determinants of bone health. J Nutr Elderly. 2008;27(1-2):3-27.
120. Larson-Meyer DE, Willis KS. Vitamin D and athletes. Curr Sports Med Rep. 2010;9(4):220-6.

121. Ogan D, Pritchett K. Vitamin D and the athlete: risks, recommendations, and benefits. Nutrients. 2013;5(6):1856-68.

122. Woolf K, Manore MM. B-vitamins and exercise: does exercise alter requirements? Int J Sport Nutr Exerc Metab. 2006;16(5):453-84.

123. Lukaski HC. Vitamin and mineral status: effects on physical performance. Nutrition. 2004;20(7-8):632-44.

124. Peeling P, Dawson B, Goodman C, Landers G, Wiegerinck ET, Swinkels DW, Trinder D. Effects of exercise on hepcidin response and iron metabolism during recovery. Int J Sport Nutr Exerc Metab. 2009;19(6):583-97.

125. Hallberg $L$, Brune $M$, Rossander $L$. The role of vitamin $C$ in iron absorption. Int J Vitam Nutr Res. 1989;30:103-8.

126. Hurrell RF, Reddy MB, Juillerat M, Cook JD. Meat protein fractions enhance nonheme iron absorption in humans. J Nutr. 2006;136(11):2808-12.

127. Brownlie TIV, Utermohlen V, Hinton PS, Haas JD. Tissue iron deficiency without anemia impairs adaptation in endurance capacity after aerobic training in previously untrained women. Am J Clin Nutr. 2004:79(3):437-43.

128. Garvican LA, Saunders PU, Cardoso T, Macdougall IC, Lobigs LM, Fazakerley R, Gore CJ. Med Sci Sports Exerc. 2014;46(2):376-85.

129. Hambidge M. Human zinc deficiency. J Nutr. 2000;5:1344-9.

130. Micheletti A, Rossi R, Rufini S. Zinc status in athletes: relation to diet and exercise. Sports Med. 2001;31(8):577-82.

131. Institute of Medicine (US) Panel on Micronutrients. 2001.

132. Rude RK. Magnesium metabolism and deficiency. Endocrinol Metab Clin North Am. 1993;22(2):377-95.

133. lannello S, Belfiore F. Hypomagnesemia. A review of pathophysiological, clinical and therapeutical aspects. Panminerva Med. 2001;43(3):177-209.

134. Nielsen FH, Lukaski HC. Update on the relationship between magnesium and exercise. Magnes Res. 2006;19(3):180-9.

135. Bohl CH, Volpe SL. Magnesium and exercise. Crit Rev Food Sci Nutr. 2002;42:533-63.

136. Knez W, Coombes J, Jenkins D. Ultra-endurance exercise and oxidative damage. Sports Medicine. 2006;36(5):429-41.

137. Yavari A, Javadi M, Mirmiran P, Bahadoran Z. Exercise-induced oxidative stress and dietary antioxidants. Asian J Sports Med. 2015; 6(1).

138. Sies H. Oxidative stress: oxidants and antioxidants. Exp Physiol. 1997;82(2):291-5

139. Mastaloudis A, Morrow JD, Hopkins DW, Devaraj S, Traber MG. Antioxidant supplementation prevents exercise-induced lipid peroxidation, but not inflammation, in ultramarathon runners. Free Radic Biol Med. 2004;36(10):1329-41.

140. Nieman DC, Henson DA, McAnulty SR, McAnulty L, Swick NS, Utter AC, Vinci DM, Opiela SJ, Morrow JD. Influence of vitamin C supplementation on oxidative and immune changes after an ultramarathon. J Appl Physiol. 2002;92(5):1970-7.

141. Knechtle B, Knechtle P, Schulze I, Kohler G. Vitamins, minerals and race performance in ultra-endurance runners-Deutschlandlauf 2006. Asia Pac J Clin Nutr. 2008;17(2):194-8.

142. Powers SK, DeRuisseau KC, Quindry J, Hamilton KL. Dietary antioxidants and exercise. J Sports Sci. 2004;22(1):81-94.

143. Pandey KB, Rizvi SI. Plant polyphenols as dietary antioxidants in human health and disease. Oxidative Med Cell Longev. 2009;2:270-8. doi:10.4161/oxim.2.5.9498.

144. Erdman JW, Balentine D, Arab L, Beecher G, Dwyer JT, Folts J, Burrowes J. Flavonoids and heart health: proceedings of the ILSI North America flavonoids workshop, May 31-June 1, 2005, Washington, DC. J Nutr. 2007;3(1):718-37.

145. Richards JC, Lonac MC, Johnson TK, Schweder MM, Bell C. Epigallocatechin-3-gallate increases maximal oxygen uptake in adult humans. Med Sci Sports Exerc. 2010:42:739-44. doi:10.1249/MSS.0b013e3181bcab6c.

146. Venables MC, Hulston CJ, Cox HR, Jeukendrup AE. Green tea extract ingestion, fat oxidation, and glucose tolerance in healthy humans. Am J Clin Nutr. 2008;87(3):778-84.

147. Dean S, Braakhuis A, Paton C. The effects of EGCG on fat oxidation and endurance performance in male cyclists. Int J Sport Nutr Exerc Metab. 2009;19(6):624-44. 
148. Eichenberger P, Colombani PC, Mettler S. Effects of 3-week consumption of green tea extracts on whole-body metabolism during cycling exercise in endurance-trained men. Int J Vitam Nutr Res. 2009;79:24-33. doi:10.1024/0300-9831.79.1.24.

149. Jowko E, Sacharuk J, Balasinska B, Wilczak J, Charmas M, Ostaszewski $P$, Charmas R. Effect of a single dose of green tea polyphenols on the blood markers of exercise-induced oxidative stress in soccer players. Int J Sport Nutr Exerc Metab. 2012;22(6):486-96.

150. Petrovski G, Gurusamy N, Das DK. Resveratrol in cardiovascular health and disease. Ann NY Acad Sci. 2011;1215:22-33. doi:10.1111/j.1749-6632.2010.05843.x.

151. Gliemann L, Schmidt JF, Olesen J, Bienso RS, Peronard SL, Grandjean SU, Hellsten Y. Resveratrol blunts the positive effects of exercise training on cardiovascular health in aged men. J Physiol. 2013. doi:10.1113/ jphysiol.2013.258061.

152. Hart N, Sarga L, Csende Z, Koltai E, Koch LG, Britton SL, Radak Z. Resveratrol enhances exercise training responses in rats selectively bred for high running performance. Food Chem Toxicol. 2013;61:53-9. doi:10.1016/j.fct.2013.01.051

153. Wu RE, Huang WC, Liao CC, Chang YK, Kan NW, Huang CC. Resveratrol protects against physical fatigue and improves exercise performance in mice. Molecules. 2013;18:4689-702. doi:10.3390/molecules18044689.

154. Dolinsky VW, Jones KE, Sidhu RS, Haykowsky M, Czubryt MP, Gordon T, Dyck JR. Improvements in skeletal muscle strength and cardiac function induced by resveratrol during exercise training contribute to enhanced exercise performance in rats. J Physiol. 2012. doi:10.1113/ jphysiol.2012.230490.

155. Hart N, Sarga L, Csende Z, Koch LG, Britton SL, Davies KJ, Radak Z. Resveratrol attenuates exercise-induced adaptive responses in rats selectively bred for low running performance. Dose-Response. 2013:12:57-71. doi:10.2203/dose-response.13-010.Radak.

156. Lagouge M, Argmann C, Gerhart-Hines Z, Meziane H, Lerin C, Daussin F, Auwerx J. Resveratrol improves mitochondrial function and protects against metabolic disease by activating SIRT1 and PGC-1alpha. Cell. 2006;127:1109-22.

157. Mayers JR, Iliff BW, Swoap SJ. Resveratrol treatment in mice does not elicit the bradycardia and hypothermia associated with calorie restriction. FASEB J. 2009:23:1032-40. doi:10.1096/fi.08-115923.

158. Silva MM, Santos MR, Caroco G, Rocha R, Justino G, Mira L. Structureantioxidant activity relationships of flavonoids: a re-examination. Free Radic Res. 2002;36(11):1219-27.

159. Wadley GD, McConell GK. Effect of nitric oxide synthase inhibition on mitochondrial biogenesis in rat skeletal muscle. J Appl Physiol. 2007:102(1):314-20.

160. Harwood M, Danielewska-Nikiel B, Borzelleca JF, Flamm GW, Williams GM, Lines TC. A critical review of the data related to the safety of quercetin and lack of evidence of in vivo toxicity, including lack of genotoxic/carcinogenic properties. Food Chem Toxicol. 2007:45:2179-205.

161. Davis JM, Murphy EA, Carmichael MD. Effects of the dietary flavonoid quercetin upon performance and health. Curr Sports Med Rep. 2009:8:206-13. doi:10.1249/JSR.0b013e3181ae8959.

162. Davis JM, Carlstedt CJ, Chen S, Carmichael MD, Murphy EA. The dietary flavonoid quercetin increases $\mathrm{VO}(2 \mathrm{max})$ and endurance capacity. Int J Sport Nutr Exerc Metab. 2010;20(1):56-62.

163. MacRae HS, Mefferd KM. Dietary antioxidant supplementation combined with quercetin improves cycling time trial performance. Int J Sport Nutr Exerc Metab. 2006;16(4):405-19.

164. Nieman DC, Williams AS, Shanely RA, Jin F, McAnulty SR, Triplett NT, Henson DA. Quercetin's influence on exercise performance and muscle mitochondrial biogenesis. Med Sci Sports Exerc. 2010;42(338):345 doi:10.1249/MSS.0b013e3181b18fa3.

165. Utter AC, Nieman DC, Kang J, Dumke CL, Quindry JC, MCAnulty SR, McAnulty LS. Quercetin does not affect rating of perceived exertion in athletes during the western states endurance run. Res Sports Med. 2009:17(71):83. doi:10.1080/15438620902901474.

166. Sharp MA, Hendrickson NR, Staab JS, McClung HL, Nindl BC, Michniak Kohn BB. Effects of short-term quercetin supplementation on soldier performance. J Strength Cond Res. 2012;26(Suppl 2):S53-60.

167. Nieman DC, Henson DA, Maxwell KR, Williams AS, McAnulty SR, Jin F, Lines TC. Effects of quercetin and EGCG on mitochondrial biogenesis and immunity. Med Sci Sports Exerc. 2009;41:1467-75. doi:10.1249/ MSS.0b013e318199491f.

168. Ganio MS, Armstrong LE, Johnson EC, Klau JF, Ballard KD, MichniakKohn B, Maresh CM. Effect of quercetin supplementation on maximal oxygen uptake in men and women. J Sports Sci. 2010;28:201-8. doi:10.1080/02640410903428558

169. Cureton KJ, Tomporowski PD, Singhal A, Pasley JD, Bigelman KA, Lambourne K, Zhao Q. Dietary quercetin supplementation is not ergogenic in untrained men. J Appl Physiol. 2009;107:1095-104. doi:10.1152/ japplphysiol.00234.2009

170. Cheuvront SN, Ely BR, Kenefick RW, Michniak-Kohn BB, Rood JC, Sawka $M N$. No effect of nutritional adenosine receptor antagonists on exercise performance in the heat. Am J Physiol Regul Integr Comp Physiol. 2009;296:R394-401. doi:10.1152/ajpregu.90812.2008.

171. Bigelman KA, Fan EH, Chapman DP, Freese EC, Trilk JL, Cureton KJ. Effects of six weeks of quercetin supplementation on physical performance in ROTC cadets. Mil Med. 2010;175(10):791-8.

172. Nieman DC, Henson DA, Davis JM, Dumke CL, Gross SJ, Jenkins DP, Mayer EP. Quercetin ingestion does not alter cytokine changes in athletes competing in the western states endurance run. J Interferon Cytokine Res. 2007;27:1003-11. doi:10.1089/jir.2007.0050.

173. Quindry JC, MCAnulty SR, Hudson MB, Hosick P, Dumke C, McAnulty LS, Nieman D. Oral quercetin supplementation and blood oxidative capacity in response to ultramarathon competition. Int J Sport Nutr Exerc Metab. 2008;18(6):601-16.

174. Frohnauer A, Schwanke M, Kulow W, Kohler G, Knechtle B. No effect of prerace supplementation with vitamins and minerals on performance in an ultra-endurance race. Pak J Nutr. 2008;7(2):283-6.

175. Pfeiffer B, Stellingwerff T, Hodgson AB, Randell R, Pöttgen $K$, Res $P$, Jeukendrup AE. Nutritional intake and gastrointestinal problems during competitive endurance events. Med Sci Sports Exerc. 2012;44(2):344-51.

176. Stuempfle KJ, Hoffman MD. Gastrointestinal distress is common during a 161-km ultramarathon. J Sports Sci. 2015;33(17):1814-21.

177. Stuempfle KJ, Hoffman MD, Hew-Butler T. Association of gastrointestinal distress in ultramarathoners with race diet. Int J Sport Nutr Exerc Metab. 2013;23(2):103-9.

178. Peters HP, van Schelven FW, Verstappen PA, de Boer RW, Bol E, Erich WB, de Vries WR. Gastrointestinal problems as a function of carbohydrate supplements and mode of exercise. Med Sci Sports Exerc. 1993;25(11):1211-24.

179. Maughan RJ, Rehrer NJ, McLaughlin J, Wasse LK. Importance of gastrointestinal function to athletic performance and health. Encyclopaedia Sports Med. 2013:19:526-38.

180. Pfeiffer B, Cotterill A, Grathwohl D, Stellingwerff T, Jeukendrup AE. The effect of carbohydrate gels on gastrointestinal tolerance during a 16-km run. Int J Sport Nutr Exerc Metab. 2009;19(5):485-503.

181. Jeukendrup $A E$, Jentjens R. Oxidation of carbohydrate feedings during prolonged exercise: current thoughts, guidelines and directions for future research. Sports Med. 2000;29(6):407-24.

182. Peters HP, Zweers M, Backx FJ, Bol E, Hendriks ER, Mosterd WL, de Vries WR. Gastrointestinal symptoms during long-distance walking. Med Sci Sports Exerc. 1999;31(6):767-73.

183. Knechtle B, Chandler C, Pitre J. Food habits and use of supplements in ultraendurance cyclists - the race across America (RAAM) 2006. Sportmedizin und Sporttraumatologie. 2007;55(3):102-6.

184. Zimberg IZ, Crispim CA, Juzwiak CR, Antunes HK, Edwards B, Waterhouse J, de Mello MT. Nutritional intake during a simulated adventure race. Int J Sport Nutr Exerc Metab. 2008;18(2):152-68.

185. Jeukendrup A. A step towards personalized sports nutrition: carbohydrate intake during exercise. Sports Medicine. 2014;44(1):25-33.

186. Ferraris RP. Dietary and developmental regulation of intestinal sugar transport. Biochem J. 2001;360(2):265-76.

187. Cox GR, Clark SA, Cox AJ, Halson SL, Hargreaves M, Hawley JA, Jeacocke N, Snow RJ, Yeo WK, Burke LM. Daily training with high carbohydrate availability increases exogenous carbohydrate oxidation during endurance cycling. J Appl Physiol. 1985;9(1):126-34.

188. Gisolfi CV. Is the Gl system built for exercise? News Physiol Sci. 2000;15:114-9.

189. Fisher RL, McMahon LF Jr, Ryan MJ, Larson D, Brand M. Gastrointestinal bleeding in competitive runners. Dig Dis Sci. 1986;31:1226-8. 
190. Fogoros R. Runner's trots: gastrointestinal disturbances in runners. JAMA. 1980:243(17):1743-4.

191. Carrio I, Estorch M, Serra-Grima R, Ginjaume M, Notivol R, Calabuig R, Vilardell F. Gastric emptying in marathon runners. Gut. 1989;30(2):152-5.

192. Harris A, Lindeman AK, Martin BJ. Rapid orocecal transit in chronically active persons with high energy intake. J Appl Physiol. 1991;70(4):1550-3.

193. Van Zyl CG, Lambert EV, Hawley JA, Noakes TD, Dennis SC. Effects of medium-chain triglyceride ingestion on fuel metabolism and cycling performance. J Appl Physiol. 1996;80(6):2217-25.
194. Kressler J, Millard-Stafford M, Warren GL. Quercetin and endurance exercise capacity: a systematic review and meta-analysis. Med Sci Sport Exerc. 2011;43(12):2396-404.

195. Ryder JJ, Grantham NJ, Kellett DW, McNaughton L, Lovell R, Jones GE. Marathon Des Sables: a scientific case study. Res Sports Med. 2004;12(1):33-44.

196. US Anti-Doping Agency: fluids and hydration. 2014.

\section{Submit your next manuscript to BioMed Central and we will help you at every step:}

- We accept pre-submission inquiries

- Our selector tool helps you to find the most relevant journal

- We provide round the clock customer support

- Convenient online submission

- Thorough peer review

- Inclusion in PubMed and all major indexing services

- Maximum visibility for your research

Submit your manuscript at www.biomedcentral com/submit
(O) Biomed Central 